\title{
Thomas Sydenham y la individualización de la escarlatina
}

ENRIQUE LAVAL R.*

\section{Thomas Sydenham and the identification of Scarlet Fever}

Algunos autores han interpretado la epidemia ocurrida en Atenas, el año 430 a.C., descrita por Tucídides, como "escarlatina maligna", aunque no hay certeza de que esta enfermedad fuera conocida en la antigüedad clásica. En la Edad Media, relato de médicos árabes, sobre una afección que llamaban "morbilli", también fueron relacionados con la escarlatina, pero sus descripciones tan vagas, no permitieron afirmar de manera concluyente la existencia de dicha patología en aquella época. Entre ellos destacaron Avicena (979-1037) y Rhazes (865-925). Este último, autor de una magistral reseña de la viruela, distinguiéndola claramente del sarampión, separando así las dos únicas enfermedades infecciosas de carácter endémico que conocían los árabes ${ }^{1,2}$.

En el siglo XVI, Gian Filippo Ingrasia fue el primero en efectuar descripciones clínicas de una enfermedad posteriormente reconocida como escarlatina, que figuran en su libro de Tumoribus Praeter Naturam, escrito entre 1533 y 1556. La llamó "rosalia o rosania", diferenciándola netamente del sarampión. A principio del siglo XVII, Döring y muy especialmente Serenert, señalan su exantema característico ${ }^{3,4}$. Pero fue Thomas Sydenham (1624-1689), quien en 1676 individualizó definitivamente la enfermedad a la que designó como Febris Scarlatinae o Escarlatina Simplex. Los cuadros clínicos por él observados eran tan leves que consistían, en su opinión, nada más que de un exantema y supuso que la escarlatina "apenas merecía el nombre de enfermedad". Transcurridos 15 años, tuvo la ocasión de convencerse que también podían producirse formas graves y malignas, que "en nada eran inferiores a la peste”. Pasarían muchos años para que se descubriera que aquéllas eran ocasionadas, casi siempre, por la toxina A del estreptococo $\beta$ hemolítico y las más moderadas o leves, por la toxina $\mathrm{B}$ o $\mathrm{C}$, comprobándose paulatinamente "las bien conocidas tendencias cíclicas de la patogenicidad de dicho bacterio" ${ }_{5,6}$.

En el año 1740, Huxhan llamó la atención sobre la importancia de la angina en el proceso escarlatinoso y Trousseau en 1861, consigna nada menos que en cuarenta páginas de sus célebres "Clínicas del Hotel Dieu", la más completa y minuciosa clínica de la escarlatina ${ }^{3,4,7}$.

Durante los siglos XVI al XVIII, "va $a$ edificarse en el mundo occidental el pensamiento patológico moderno". Se introduce una gran variación dentro del estudio clínico de las enfermedades: es el concepto de "especie morbosa" (entidad nosológica), siendo el aporte fecundo del gran clínico inglés de la segunda mitad del siglo XVII: Thomas Sydenham (el "Hipócrates inglés"). Este pensamiento constituye una suerte de compromiso entre la experiencia y la razón, en el que debe buscarse la clave de lo que significó Sydenham para la medicina moderna ${ }^{6}$.

Al igual que Hipócrates y posteriormente los médicos islámicos, Sydenham insistió en la necesidad de realizar una cuidadosa observación de los enfermos, utilizando y valorando una detallada historia de sus dolencias ${ }^{8}$. Fue un humilde médico práctico de Londres, que fundó su fama en la asistencia clínica, sin realizar ninguna contribución anatómica o fisiológica. Al aceptar la existencia de entidades morbosas, trató de agruparlas y de reconocer los síntomas que les son propios, separándolos de los originados por las peculariedades de los pacientes. Creó así, conjuntos de síntomas, verdaderos síndromes, a los que intentó clasificar, aunque no conociera ni el

\footnotetext{
* Servicios Médicos DIAL S.A.
} 
sustrato lesional ni los disturbios funcionales que los causaban.

En la concepción de Sydenham, las enfermedades eran producidas por el aire, la alimentación, la retención de humores, el ejercicio y las emociones, siendo combatidas en primer lugar por el poder curativo de la naturaleza. Su terapéutica se basó en el régimen higiénico-dietético, si bien introdujo el hierro como medicamento para la anemia; prestó gran consideración a la corteza de Cinchona o de quina en el tratamiento del paludismo e ideó derivados opiáceos como el "láudano de Sydenham".

De su reducida producción se destaca, entre otros, el Methodus Curandi Febres, cuya primera edición apareció en 1666. En la de 1688, expone una doctrina sobre la viruela, considerándola un proceso natural, una "licuación", que acontece en cada individuo "una vez en el transcurso de la vida". En otra publicación, Observationes Medicae (1676), refundición ampliadísima y renovada de su Methodus, que abarcaba ahora las epidemias habidas en Londres, desde 1661 hasta 1675 , caracterizó la escarlatina, como ya lo mencionamos. En forma modesta, nuevamente se refiere también aquí a la viruela, diciendo que "cual sea, empero, la esencia de esta enferme$\mathrm{dad}$, confieso sinceramente que lo ignoro, por ser mi inteligencia natural y, como la de los demás hombres, limitada". También describió otras enfermedades como la gota, la sífilis y la corea, que lleva su nombre. Tuvo además una importante actuación en la epidemia de peste bubónica, que se produjo en Londres en 1665.

En el terreno epidemiológico fue Sydenham quien restauró el olvidado concepto hipocrático de la "constitución epidémica", (genio epidémico) interpretándolo, en sentido restringido, como "aspecto" meteorológico. Para él, la enfermedad epidémica, sería "determinada, por una alteración secreta e inexplicable de la atmósfera, que infecta los cuerpos humanos y es enfermedad que no depende del espesor especial de la sangre y de los humores, sino en cuanto han sido producidos en dichos cuerpos por la oculta influencia del aire ${ }^{2,6}$.

Epidemias de escarlatina de variada intensidad afectaron a Europa y América en el siglo XVIII. Nils Rosen von Rosenstein, catedrático de la Universidad de Upsala, en 1744, refiriéndose a la primera epidemia registrada en Suecia, observa: "la escarlatina es a veces en algunas personas tan favorable y benigna que el paciente requiere sólo buenos cuidados generales; en otras es tan maligna que puede causarle la muerte en uno o dos días".

$\mathrm{Su}$ gravedad fue tan extrema en Inglaterra en el siglo XVIII que en su desesperación la gente recurría a los más extraños e ineficaces expedientes para prevenirse como lo señala Withering, "algunos fumaban, otros masticaban tabaco; unos y otros se lavaban las manos y el rostro con "vinagre de los cuatro ladrones" (llamado así por la leyenda que cuatro ladrones, que se entre-

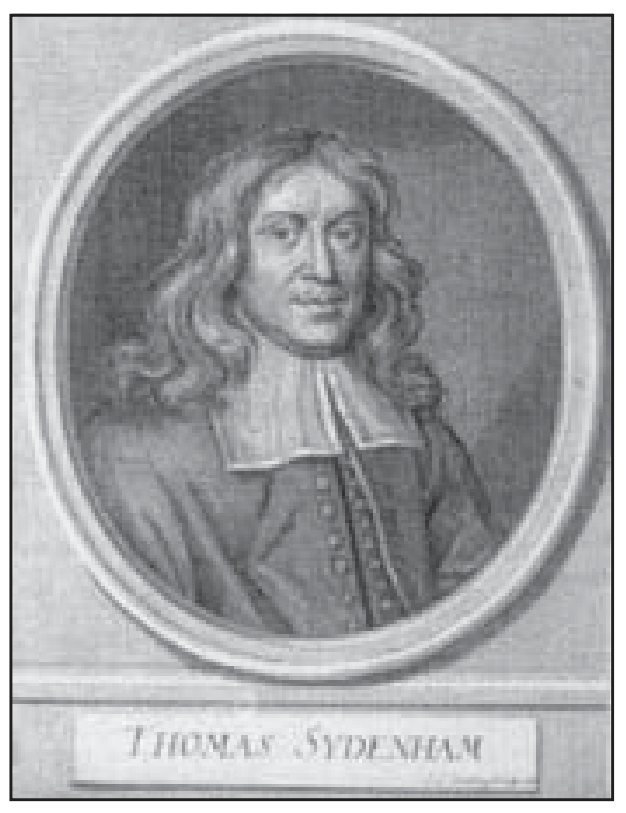

Figura 1. Thomas Sydenham (1624-1689).

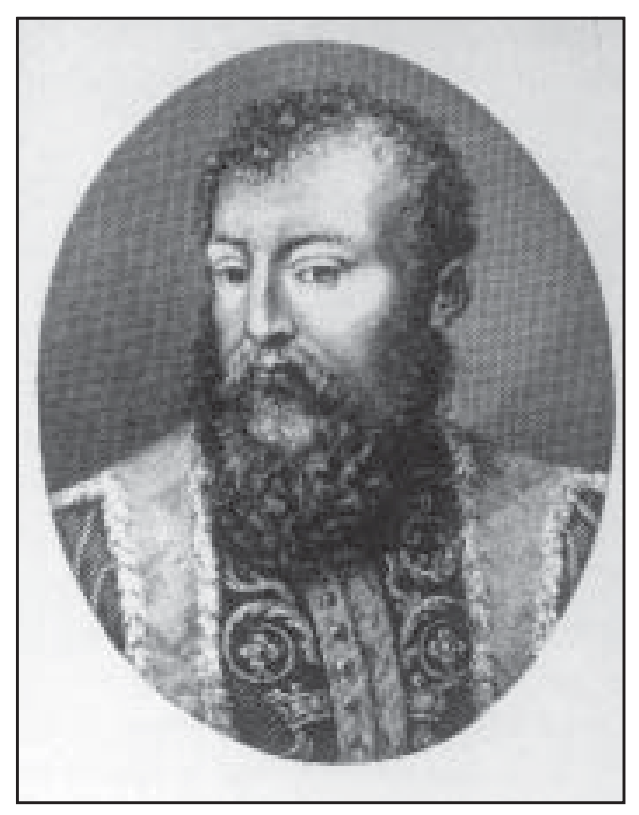

Figura 2. Gian Filippo Ingrasia (1510-1580). 
garon al saqueo en Londres durante la epidemia de peste bubónica de 1665, se libraron del contagio, gracias a su ingestión con los alimentos); muchos emplastos de alcanfor en la boca del estómago y no faltaban los que ingerían amargo de Angostura o vino de Oporto".

Pierre Bretonneau, en cuyo trabajo publicado en 1826, distinguió claramente la escarlatina de la difteria, decía que en su actividad clínica en Tours, no recordaba un solo caso mortal, entre 1799 y 1822 ; en cambio la epidemia de escarlatina de 1824 fue tan grave que le indujo a considerar dicha enfermedad en la misma categoría de malignidad que la peste bubónica, el tifus exantemático o el cólera.

Durante la primera mitad del siglo XIX, la escarlatina invadió muchas partes del mundo anteriormente indemnes, como Madera, Groenlandia, Australia, Nueva Zelandia, California y varios países de América del Sur. 1,7

En Chile, se menciona por primera vez la aparición de la escarlatina en el año 1827, en un informe del Protomedicato. En 1831 y 1832, hubo otra epidemia que se inició en Valparaíso pasando luego a Santiago, con casi 7.000 enfermos.

A requerimiento del Gobierno, el doctor don Nataniel Cox, en 1842, en su calidad de Protomédico, indicó las normas para la curación de aquella enfermedad, ya que en ese año se produjo una nueva epidemia, clasificando las formas clínicas de la escarlatina, de menor a mayor gravedad, en simple, anginosa y maligna. En todas se emplearon diversas infusiones de yerbas (palqui, sauco, borraja, malva, etc) sin faltar la aplicación de sanguijuelas en la garganta o en otros sitios de dolor. En la forma maligna, se agregaba aporte de líquidos importante, con té cargado, manzanilla y azafrán de Castilla. También algunas tazas de agua, con claras de huevo batidas, lavativas de almidón, aplicación de sinapismo al estómago con mostaza y cominos, siendo el uso de mixtura alcanforada con licor de acetato de amonio y jarabe de azafrán, "el medicamento que ha dado mejores resultados" $", 10$.

En la segunda mitad del siglo XIX, se comunicaron brotes epidémicos localizados en Copiapó (1875) y en Caldera, a principio de 1876. En el tratado de Medicina de Von Bergmann, se cita epidemias graves en Sudamérica, "como la de Chile en 1929".

Entre 1952 y 1981, la escarlatina presentó una tendencia sostenida y permanente hacia el alza, en el país, con brotes epidémicos cada 5 ó 6 años, para continuar con brotes esporádicos, en general no graves, en los últimos años ${ }^{4,9,10,11}$.

\section{Bibliografía}

1.- Grandes Enfermedades. Escarlatina. MD en español. Noviembre 1972. p. 66-70.

2.- Papp D, Agüero A. Breve Historia de la Medicina. Ed. La Claridad. Sao Paulo. Brasil 1994; 172-3.

3.- Brugsh Th. Tratado de Patología Médica. Tomo I. p. 324-36. Ed. labor S.A. Barcelona. españa. 1937.

4.- Bergmann G, Staehelin R, Salle, V. Tratado de Medicina. Enfermedades Infecciosas. Tomo I. p. 359-40. Ed. Labor S.A. Barcelona. españa. 1942.

5.- Laval R E. La infección por el estreptococo beta hemolítico del grupo A: ¿vuelta al pasado? Rev Chil Infect 1994; 11: 73-81.

6.- Lain Entralgo P. Historia Universal de la Medicina. Tomo IV. p. 297-306. Barcelona. españa. 1973.

7.- Castiglione A. Historia de la Medicina. p. 406, 537, 606. Ed. Salvat. Barcelona. España. 1941.

8.- Sydenham T. The Renaissance. Disease and its treatment. BBC Medicine through time. p 1, 2003. http://www.bbc.co.uk.educative/medicine/nonintrenaiss/ $\mathrm{dt} / \mathrm{redtbi} 4 . \mathrm{shtml}$

9.- Laval R E. Notas históricas. Escarlatina en Chile. Rev Chil Infect 1984; 2: 135-6.

10.- Olea A. Historia de las Enfermedades Infecciosas en Chile. El Vigía 2000; 3: 5-6.

11.- Enfermedades de Notificación Obligatoria. Ministerio de Salud. Chile. 1981. 